\title{
Kolistin ve Böbrek Yetmezliği İlişskisi: Tek Merkez Deneyimi
}

\author{
Colistin and Renal Failure: Single Center Experience
}

Havva Kocayiğit ${ }^{1}$, Kezban Özmen Süner ${ }^{2}$, Özge Pekşen ${ }^{3}$, Halil Kızılışık³ ${ }^{3}$ Ali Fuat Erdem ${ }^{3}$

${ }^{1}$ Sakarya Üniversitesi Eğitim ve Araştırma Hastanesi Anesteziyoloji ve Reanimasyon Kliniği

${ }^{2}$ Sakarya Üniversitesi Ĕ̆itim ve Araştırma Hastanesi Yoğun bakım

${ }^{3}$ Sakarya Üniversitesi, Anesteziyoloji ve Reanimasyon $A B D$

\author{
Yazışma Adresi / Correspondence: \\ Havva Kocayiğit \\ Sakarya Universitesi Eğitim ve Araştırma Hastanesi Anesteziyoloji ve Reanimasyon Kliniği, Sakarya \\ T: +905425950020 E-mail : havvakocayigit@gmail.com \\ Geliş Tarihi / Received : 07.02.2021 Kabul Tarihi / Accepte: 08.06.2021 \\ Orcid : \\ Havva Kocayiğit: https://orcid.org/0000-0002-8719-7031 \\ Kezban Özmen Süner: https://orcid.org/0000-0002-9822-4031 \\ Özge Pekșen: https://orcid.org/0000-0001-8815-7894 \\ Halil Kızılışık: https://orcid.org/0000-0001-9860-0271 \\ Ali Fuat Erdem: https://orcid.org/0000-0001-6994-397X \\ ( Sakarya Tip Dergisi / Sakarya Med J 2021, 11(3):576-582 ) DOI: 10.31832/smj.876264
}

\footnotetext{
$\ddot{\mathrm{O} z}$

Amaç Hastane kaynaklı infeksiyonlar ve bu infeksiyonlara neden olan çoklu ilaç direnci olan gram negatif mikroorganizmalar nedeniyle yoğun bakımlarda kolistin sık kullanılmaktadır. Kolistine bağlı nefrotoksisite sık görülen bir yan etkidir. Bu çalışmada yoğun bakımda kullanılan kolistin nefrotoksisitesine bağlı renal replasman tedavisi (RRT) ihtiyacı gelişen hastaların genel özelliklerini, tedavilerini ve sonuçlarını incelemeyi amaçladık.

Gereç ve Her hastanın yaş, cinsiyet, yoğun bakıma yatış tanısı, ek hastalıkları, alınan kültür yerleri ve kültürde üreyen mikroorganizmalar, yoğun bakıma kabul esnasındaki Acute Yöntemler Physiology, Assessment and Chronic Health Evaluation (APACHE II) skoru ve Carlson Comorbidity İndeks (CCI) skorları kaydedildi. Daha sonra hastaların kolistin tedavisine başlandığı gün ve tedavinin sonlandırıldığı gün alınan kan örneklerindeki laboratuar parametreleri kaydedildi. Ayrıca hastalara yatıștan itibaren kolistin tedavisine başlanma günü, total verilen kolistin dozu, hastaların hemodiyaliz ihtiyacı, toplam yoğun bakım yatıs günü ve mortalite oranları kaydedildi. Gruplar arasındaki klinik ve laboratuar verilere ilişkin farklılıklar istatistiksel olarak değerlendirildi. $\mathrm{p}<0,05$ anlamlı kabul edildi.

Bulgular Yoğun bakımda kolistin kullanan hastalarda \%33 oranında renalreplasman tedavisi ihtiyacı geliştiği görüldü. RRT için tedavi öncesi kreatinin değerleri bağımsız risk faktörleri olarak saptanmıștır. Bunun dıșında hastaların yaşı, APACHE II skorları, kolistin tedavisi öncesi üre ve eGFR değerleri, kolistin tedavi dozu ve total kolistin verilme günü, renal replasman tedavisi ihtiyacı belirlendi.

Sonuç Kolistin tedavisine bağlı RRT ihtiyacı sık görülmektedir. Tedavi öncesi kreatin değerleri RRT gelişmesi açısından bağımsız risk faktörü olarak bulunmuştur.

Anahtar yoğun bakım; kolistin; böbrek yetmezliğ

Kelimeler

Abstract

Objective Colistin is frequently used in intensive care units due to gram-negative microorganisms that are multi-drug resistant causing hospital-acquired infections. Colistin-related nephrotoxicity is a common side effect. In this study, we aimed to examine the general characteristics, treatments and outcomes of patients who developed renal replacement therapy (RRT) need due to colistin nephrotoxicity in the intensive care unit.

Materials Age, gender, diagnosis of ICU admission, additional diseases, culture locations and microorganisms grown in culture, Acute Physiology, Assessment and Chronic Health Evaluation (APACHE and Methods II) score and Carlson Comorbidity Index (CCI) scores were recorded during admission to intensive care unit. Then, the laboratory parameters of the blood samples taken on the day the patients started colistin therapy and the day the treatment was terminated were recorded. In addition, the day of initiation of colistin therapy, total dose of colistin given, hemodialysis need of the patients, total intensive care hospitalization day and mortality rates were recorded. Differences in clinical and laboratory data between groups were evaluated statistically. $p<0.05$ is considered significant.

Resulrs It was observed that the need for renal replacement therapy developed in $33 \%$ of patients using colistin in the intensive care unit. Pre-treatment creatinine values were determined as independent risk factors for RRT. Apart from this, the age of the patients, APACHE II scores, urea and eGFR values before colistin therapy, colistin treatment dose and total colistin administration day renal replacement therapy need were determined.

Conclusion The need for RRT related to colistin therapy is common. Pre-treatment creatine levels were found to be an independent risk factor for the development of RRT.

Keywords : intensive care; colistin; renal failure
} 


\section{GíRiș}

Hastane kaynaklı infeksiyonlar, hastanın hastaneye yatış nedeninden bağımsız olarak morbidite ve mortalitesini artıran önemli komplikasyonlardandır. Ayrıca hastanede kalış süresini uzatıp ek tedavilere neden olarak yatış maliyetini de arttırırlar. Hastanelerin yoğun bakım üniteleri (YBÜ) hastane geneline göre dirençli mikroorganizmaların daha çok izole edildiği birimlerdir. Hastane genelinde hastane enfeksiyon insidansı \%5-10 iken YBÜ'nde bu oran \%20-25 olarak bildirilmektedir., ${ }^{1,2}$

Hastane kaynaklı infeksiyonlar ve bu infeksiyonlara neden olan gram negatif bakterilerin sıklığı giderek artmaktadır. $\mathrm{Bu}$ infeksiyonlarda yaşanan en büyük problem çoklu ilaç direnci nedeniyle tedavi seçeneklerinin kısıtlı olması ve bunun sonucunda morbidite ve mortalitenin artmasıdır. ${ }^{3}$ Çoklu ilaç direnci gösteren mikroorganizmalara karşı tek alternatif olan kolistinyoğun bakımlarda sık kullanılmaktadir.

1947'de İngiltere' de Bacilluspolymyxa kültürlerinden çeşitli polimiksinler elde edilmiştir. ${ }^{4}$ Bunlardan sadece polimiksin B ve E terapötik değere sahip bulunmuşlar. Daha sonra polimiksin-E diğer adıyla kolistin elde edilmiştir. ${ }^{5}$ Kolistin, kolismetat sodyum veya kolistin sülfat olarak da bilinir. Kolistin, Pseudomonas aeruginosa, Acinetobacter baumannii, Klebsiella pneumonia, Salmonella, Shigella, Citrobacter türleri, Yersinia pseudotuberculosis, Morganella morganii ve Haemophilus influenza dahil olmak üzere çoğu gram-negatif organizmaya karşı aktiviteye sahiptir. ${ }^{6}$ 1960'larda kolitsin kullanılmaya başlandıktan sonra nefrotoksisiteye neden olması sebebiyle 1980'lerde terk edilmiştir. Günümüzde çoklu ilaç direnci gösteren mikroorganizmalarda artış ve bu mikroorganimalara karşı tek alternatif olması nedeni ile kolitsin kullanımı yeniden gündeme gelmiştir. Yapılan retrospektif çalışmalarda, yoğun bakım hastalarında kolistine bağlı nefrotoksisite oranları \%31-61 gibi geniş bir aralıkta yer almaktadır.-13

$\mathrm{Bu}$ çalışmada yoğun bakımda çoklu ilaç direnci gösteren mikroorganizmalara bağlı enfeksiyonların tedavisinde kullanılan kolistin nefrotoksisitesine bağlı RRT ihtiyacı gelişen hastaların genel özelliklerini, tedavilerini ve sonuçlarını incelemeyi amaçladık.

\section{GEREÇ ve YÖNTEMLER}

Çalışmamız kesitsel tanımlayıcı çalışma olup Sakarya Üniversitesi girişimsel olmayan klinik araştırmalar etik kurul onayı (tarih:09.11.2020 no:611) ardından, Ocak 2019 ile Aralık 2019 yıllarıarasında Sakarya Üniversitesi Eğitim ve Araştırma Hastanesi Anestezi Yoğun Bakım Ünitesi'nde kolistin tedavisi almış olan hastaların verileri retrospektif olarak incelendi. Çalışmaya dahile dilme kriterleri 18-80 yaş arası, anestezi yoğun bakım ünitesi yatış sürecinde kolistin (Colimycin ${ }^{\oplus}$, KoçakFarma, İstanbul, Türkiye) tedavisi almış olan hastalar olarak belirlendi. Kolistin tedavisi öncesinde kronik böbrek yetmezliği olan veya kolistin tedavisi öncesinde akut böbrek yetmezliği gelişen hastalar, kolistin tedavisi alırken eksitus olan hastalar çalışma dışı bırakıldı. Hastanemizde rutin olarak RRT başlanması için Leite ve arkadaşlarının 2013'te yayıladıkları AKIN kriterleri kullanılmaktadır. Buna göre: Üremik semptomlar ile birlikte azotemi (BUN>150 mg/ dL), Medikal tedaviye dirençli hiperkalemi $(\mathrm{K}>5,5 \mathrm{mEq} / \mathrm{L})$, Arteriyel $\mathrm{pH}<7,2$ ve Serum bikarbonat < 16 mEq/L ve İdrar çıkışı < 100 ml/12 saat veya Diüretik dirençli oligoanüri varsa hastalara RRT tedavisi başlanır. ${ }^{14}$

Her hastanın yaş, cinsiyet, yoğun bakıma yatış tanısı, ek hastalıkları, alınan kültür yerleri ve kültürde üreyen mikroorganizmalar, yoğun bakıma kabul esnasındaki APACHE II skoru ve CCİ skorları kaydedildi. Daha sonra hastaların kolistin tedavisine başlandığg gün ve tedavinin sonlandırıldığı gün alınan kan örneklerindeki laboratuar parametreleri kaydedildi. Ayrıca hastalara yatıştan itibaren kolistin tedavisine başlanma günü, total verilen kolistin dozu, hastaların hemodiyaliz ihtiyacı, toplam yoğun bakım yatış günü ve mortalite oranları kaydedildi. Daha sonra değerlendirilen bu parametrelerin renal replasman tedavisi ihtiyacı açısından risk faktörü olup olmaması bi- 
nary logistic regresyon analizi ile değerlendirildi.

\section{İstatistiksel analiz}

IBM SPSS Statistics 22 programı kullanılarak istatistiksel incelemeler yapıldı. Sayısal değişkenlerin dağılımı Kolmogorovsmirnov ile değerlendirildi. Kategorik değişkenler için veriler sayı, yüzde olarak belirtilirken sürekli değişkenler için ortalama \pm standart sapma veya median (interquartil range) olarak belirtildi. Kategorik değişkenler için ki-kare ve Fisher'sexact test kullanıldı. Dağılımı normal olan sürekli değişkenler Student T-Test ile, dağılımı normal olmayan sürekli değişkenler Mann whitney-U test ile karşılaştırıldı. Bağımsız değişkenlerin akut böbrek yetmezliği üzerine olan etkilerini değerlendirmek için binary lojistik regresyon testi uyguland. $\mathrm{p}<0,05$ anlamlı olarak kabul edildi.

\section{BULGULAR}

Çalışma tarihleri arasında toplam 69 hastaya kolistin tedavisinin uygulandığı saptandı. Bu hastalardan 6'sı kolistin tedavisi öncesinde renalreplasman tedavisi aldığı, 3 hastanın RRT başlandıktan sonra ilk 24 saat içinde eksitus olduğu görüldü ve kriterlere uyan 60 hastanın verileri analiz edildi.

Yoğun bakımda takip edilmiş olan 60 hastanın yaş ortalaması 61,1 \pm 19,2 olarak saptandı. Hastaların 32 (53,3\%)'sinin kadın, 28 (46,7\%)'inin erkek olduğu görüldü. Hastaların yoğun bakım yatış nedenleri arasında postresüsitasyon sendromu (28,3\%), sepsis $(20,0 \%)$ ve pnömoni $(18,3 \%)$ en sık nedenler olup, en sık eşlik eden komorbiditeler diyabetes mellitus (18,3\%), hipertansiyon (16,7\%) ve koroner arter hastalığ $(15,0 \%)$ idi. Hastalardan alınan örneklerdeki üremeler değerlendirildiğinde trakeal aspiratta üreme 18 $(30,0 \%)$ hastada, kanda üreme $16(26,7 \%)$ hastada, santral venöz kataterde üreme 10 (16,7\%) hastada saptandı. Üreyen mikroorganizmalar arasında $24(40 \%)$ hastada Acinetobacter baumannii, 14 (23,3\%) hastada Klebsiella pneumoniae, 8 (13,3\%) hastada Pseudomonas aeruginosa üremesi olduğu görüldü. Hastaların yoğun bakımlara yatı- şında değerlendirilen APACHE II skorları ortalaması 23,0 \pm 9,2, CCI skoru ortancası 4 [1-6] olarak saptandı (Tablo $1)$.

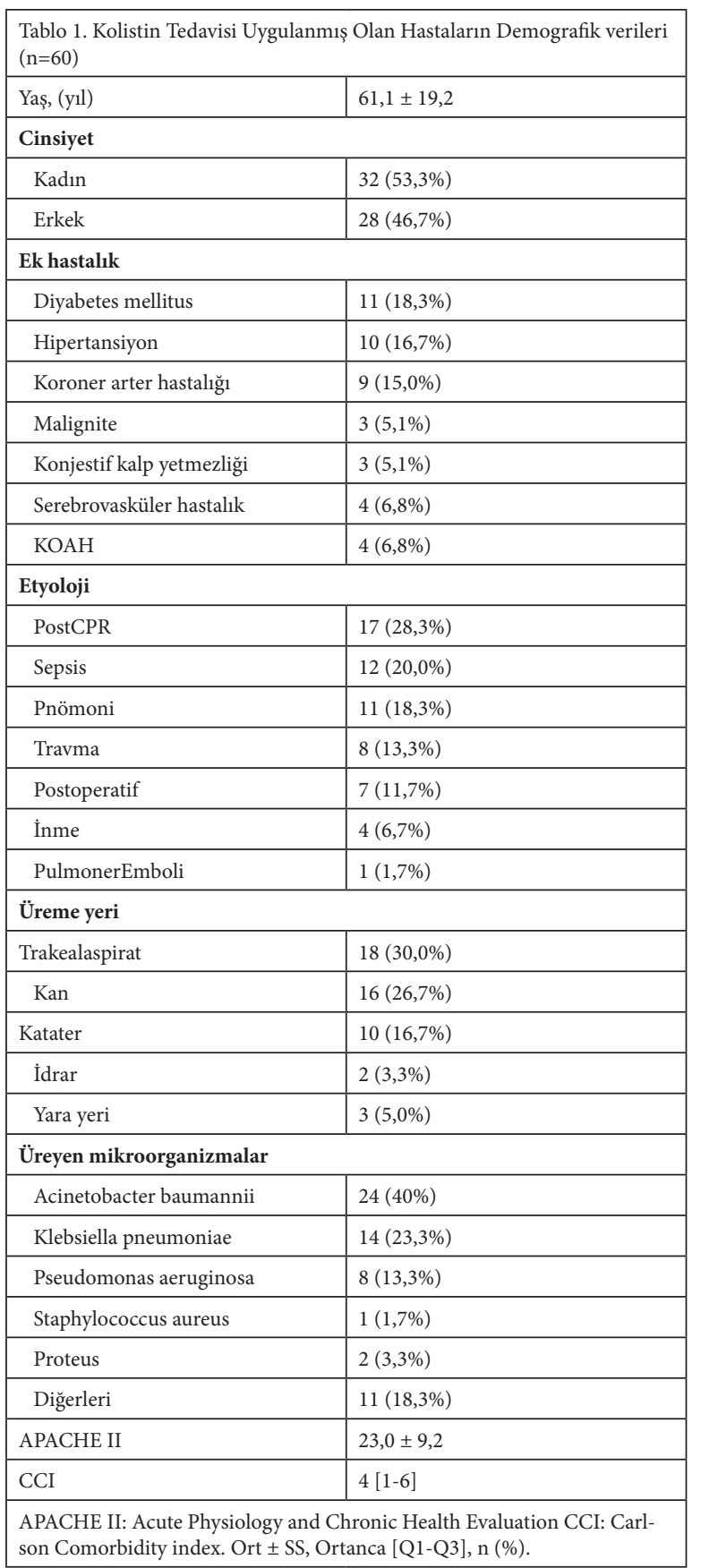


Kolistin tedavisi öncesi ve tedavi sonrası hemogram ve biyokimyasal parametreleri değerlendirildiğinde hemoglobin, beyaz küre, nötrofil, lenfosit ve platelet sayılarında bir değişiklik gözlenmedi. Fakat hastaların kolistin tedavisi sonrası kreatin ve eGFR değerlerinde istatistiksel olarak anlamlı derecede düşüklük olduğu görüldü $(\mathrm{p}<0,01)$ (Tablo 2).

Tablo 2. Kolistin tedavisi öncesi ve sonrası laboratuar parametrelerindeki değişimler

\begin{tabular}{|l|c|c|c|}
\hline & Tedavi öncesi & Tedavi sonrası & $\mathrm{p}$ \\
\hline Hemoglobin, g/dL & $8,8 \pm 1,2$ & $8,5 \pm 0,9$ & 0,223 \\
\hline Beyaz küre, $\mathrm{x} 109 / \mathrm{mL}$ & $12,9 \pm 7,2$ & $12,8 \pm 6,8$ & 0,916 \\
\hline Nötrofil, $\mathrm{x} 109 / \mathrm{mL}$ & $10,7 \pm 6,7$ & $10,5 \pm 6,3$ & 0,787 \\
\hline Lenfosit, x109/mL & $1,2 \pm 0,8$ & $1,3 \pm 0,9$ & 0,478 \\
\hline Platelet, x109/mL & $256 \pm 159$ & $253 \pm 162$ & 0,907 \\
\hline Üre, $\mathrm{mg} / \mathrm{dL}$ & $57[38-132]$ & $77[48-150]$ & 0,067 \\
\hline Kreatin, $\mathrm{mg} / \mathrm{dL}$ & $0,6[0,4-1,1]$ & $1,4[0,8-2,4]$ & $0,000^{*}$ \\
\hline eGFR & $93,5[59-127]$ & $52[25-91]$ & $0,000^{*}$ \\
\hline
\end{tabular}

eGFR: Glomerülerfiltrasyon hızı $\mathrm{p}<0.05$ istatistiksel olarak anlamlı kabul edilmiştir. Ort \pm SS, Ortanca [Q1-Q3].

Yoğun bakım yatışı sonrası kolistin tedavisi başlanma günü 19 [10-39], total kolistiin verilme dozu 3000 [1950 - 3900] ve toplam kolistin verilme günü 10 [6 -13] olarak saptandı. Hastaların 15 (25,0\%)'i hemodiyafiltrasyon,
$9(15,0 \%)$ 'u sürekli renal replasman tedavisi (4 hasta hem hemodiyafiltrasyon hem sürekli renal replasman tedavisi tedavisi almıştır.) olmak üzere $20(33,3 \%)$ hasta renal replasman tedavisi uygulandığı görüldü. Hastaların 34 $(\% 56,7)$ 'ünde vazopressör tedavisi ihtiyacı mevcut olup toplam yoğun bakım yatış süresi 44 (26-69) gün idi. Hastaların 36 (60\%)'sının eksitus olduğu saptandı (Tablo 3) RRT alan ve almayan hastalar kolistin verilme dozları ve süreleri açısından değerlendirildiğinde iki grup arasında anlamlı fark bulunamazken mortalite açısından değerlendirildiğinde RRT tedavisi alan grubun mortalitesinin RRT tedavisi almayan gruba göre anlamlı derecede yüksek olduğu saptand $1(p=0,029)$.

Renal replasman tedavisi için hastaların kolistin tedavisi öncesi kreatinin değerleri bağımsız risk faktörleri olarak saptanmıştır [p=0,048, OR:2,3 \%95 güven aralığı: 1,02598,528]. Bunun dışında hastaların yaşı, APACHE II değerleri, CCI skorları, kolistin tedavisi öncesi üre ve eGFR değerleri, kolistin tedavi dozu ve total kolistin verilme günü renal replasman tedavisi ihtiyacı için bağımsız risk faktörü olarak saptanmamıştır.

\begin{tabular}{|c|c|c|c|c|}
\hline & $\mathrm{n}=60$ & Diyaliz $(+) n=20$ & Diyaliz (-) n=40 & $\mathrm{p}$ \\
\hline Kolistin başlanma günü & 19 [10-39] & 23 [15-59] & $19[9,5-36,5]$ & 0,319 \\
\hline Total verilen kolistin dozu (mg) & $3000[1950-3900]$ & $3000[1950-3600]$ & $3000[1650-3900]$ & 0,711 \\
\hline Total kolistin verilme günü & $10[6-13]$ & $10[6-14]$ & $10[5-12,5]$ & 0,948 \\
\hline Vazopressör tedavi, n(\%) & $34(56,7)$ & $13(65)$ & $21(56,8)$ & 0,123 \\
\hline \multicolumn{5}{|l|}{ Diyaliz, n (\%) } \\
\hline $\mathrm{HDF}$ & $15(25,0 \%)$ & $15(25,0 \%)$ & \multirow{3}{*}{ - } & \multirow{3}{*}{ - } \\
\hline SRRT & $9(15,0 \%)$ & $9(15,0 \%)$ & & \\
\hline Toplam & $20(33,3 \%) \#$ & $20(33,3 \%) \#$ & & \\
\hline Yoğun bakım yatış süresi (gün) & 44 [26-69] & 64 [34-98] & $40[25-68]$ & 0,071 \\
\hline Mortalite, n(\%) & $36(60)$ & $16(80)$ & $20(50)$ & $0,029^{*}$ \\
\hline
\end{tabular}




\begin{tabular}{|c|c|c|c|}
\hline & Exp (B) (oddsratio) & $\% 95$ güven aralığ 1 & $\mathrm{p}$ \\
\hline Yaș (yıl) & 0,093 & $0,980-1,230$ & 0,106 \\
\hline APACHE II & 0,045 & $0,957-1,145$ & 0,322 \\
\hline CCI & 0,275 & $0,367-1,571$ & 0,458 \\
\hline Tedavi öncesi üre değerleri & 0,003 & $0,973-1,034$ & 0,834 \\
\hline Tedavi öncesi kreatinin değerleri & 2,307 & $1,025-98,528$ & $0,048^{*}$ \\
\hline Tedavi öncesi eGFR değerleri & 0,017 & $0,985-1,051$ & 0,297 \\
\hline Yatış sonrası kolistin verilme günü & 0,588 & $0,922-1,062$ & 0,770 \\
\hline Total kolistin dozu & 0,002 & $0,998-1,006$ & 0,312 \\
\hline Total kolistin verilme günü & 0,011 & $0,156-1,977$ & 0,364 \\
\hline Yoğun bakım yatış günü & 0,021 & $0,956-1,090$ & 0,539 \\
\hline
\end{tabular}

\section{TARTISMA}

Yoğun bakım ünitelerinde yatan hastalar, hastanede klinik tablosu en ağır seyreden, invaziv girişimlerin çok uygulandığı, parenteral antibiyotiklerin en çok kullanıldığı ve hastanede yatış süresi en fazla olan hastalardır. Bu nedenle çoklu ilaç direnci olan mikroorganizmalara bağlı infeksiyon oranları bu ünitelerde yüksektir. Bu infeksiyonların tedavisi oldukça zordur. Çoklu ilaç direnci olan mikroorganizmalara bağlı infeksiyonların tedavisinde, kolistin tek alternatif olması nedeniyle son yıllarda yoğun bakımlarda sık kullanılmaya başlanmıştır. Ancak kolistine bağlı gelişen nefrotoksisite mortaliteyi artıran önemli bir sorundur. Katyonik bir peptid olan kolistin, gram-negatif bakterilerin dış membranında bulunan ve anyonik yapıda olan lipopolisakkaridlere bağlanır ve lipopolisakkarid moleküllerini stabil halde tutan divalan katyonların $(\mathrm{Ca}+2, \mathrm{Mg}+2)$ yerini değiştirir. Dış membranda bozulma ve permeabilite artışa neden olarak bakteriyi öldürür. ${ }^{15-17}$ Ek olarak kolistin, lipopolisakkaridinlipid A kısmına bağlanarak endotoksinin etkisini bloke eder. Kolistin böbrekten atılırken tübüler reabsorpsiyona uğrar, bu sırada gerçekleşen konsantrasyon artışının nefrotoksisiteden sorumlu olduğu düşünülmeltedir. ${ }^{18}$

Çalışmalarda kolistine bağlı nefrotoksisite tanımlaması ve sınıflaması Rifle kriterlerine göre yapılmıştır. ${ }^{19}$ Çalışmamızda yoğun bakım hastalarında kolistine bağlı nefrotok- sisite, akut renal hasar olarak değil akut böbrek yetmezliği açısından değerlendirilmiş olup hastalar RRT ihtiyacı gelişip gelişmemesine göre değerlendirilmiştir ve hastanemizde RRT endikasyonu RİFLE kriterleri ile konulmaktadır.

Çalışma tarihleri arasında toplam 69 hastaya kolistin tedavisinin uygulandığg saptandı. Bu hastalardan kriterlere uygun olan 60 hastanın verileri analiz edildi. Bunların 20 (33.3\%)'sine RRT uygulandığı görüldü. Literatürde yoğun bakım hastaları arasında yapılmış olan çalışmalarda da benzer oranlarda nefrotoksisite ile karşılaşıldığı gözlendi. İnci ve arkadaşlarının yaptığı çalışmada 26 yoğun bakım hastasının \%18.7'sinde kolistine bağlı akut böbrek yetmezliği geliştiğ $1^{18}$, benzer şekilde Pogue ve arkadaşlarının hastanede yatan 126 hasta ile yaptığı bir çalışmada da \%17 oranında akut böbrek yetmezliği geliştiği bildirilmiştir. ${ }^{8}$ Bizim çalışmamızda nefrotoksisite gelişme oranlarının daha yüksek olmasının nedeninin yoğun bakımımızın 3 . Basamak oluşu nedeniyle comorbiditesi daha çok olan, daha düşkün hastaların takip edilmesi olduğu görüşündeyiz.

Farklı çalışmalarda kolistine bağlı nefrotoksisite gelişmesi verilen kolistin dozu, ileri yaş kronik obstüriktif akciğer hastalığı ve diabetus mellitus varlığı ile ilişkilendirilmiştir. ${ }^{17-19}$ Bizim çalışmamızda renal replasman ihtiyacı ile yaş, CCI, kolistin dozu, ilacın verilme süresi, yoğun bakım yatış 
günü arasında ilişki saptanmamıştır. Çalışmamızda RRT için sadece tedavi öncesi kreatin değerleri bağımsız risk faktörü olarak bulunmuştur. Önceki çalışmaların aksine Aydoğan ve arkadaşları da bizim sonuçlarımızla uyumlu olarak ileri yaşla nefrotoksisite arasında ilişki saptamamışlardır. ${ }^{20}$ Çalışmamızda litaratürle uyumlu olarak kolistin, en sık Acinetobacter baumannii üremesine bağlı hastane infeksiyonu nedeniyle kullanılmıştır. ${ }^{21-23}$ Bunu Klebsiella pneumoniae ve Pseudomonas aeruginosa üremeleri sırasıyla takip etmektedir. Yoğun bakımda pek çok etyolojik nedene bağlı hastalar yatmakta olup yatış süresi boyunca pek çok faktör renal yetmezlik ve mortalite ile ilişkili olabilmesi çalışmamızın en önemli kısıtlılıklarıdır.

Sonuç olarak yoğun bakımlarda artan kolistin kullanımı ile birlikte artan nefrotroksisite önemli bir morbidite ve mortalite nedenidir. Çoklu ilaç direnci olan mikroorganizmaların kontrolünün sağlanması ve kolistin kullanımının azaltılması için yoğun bakımlarda enfeksiyon kontrol kurallarına uyulması önemlidir. Ayrıca kolistin tedavisi alan hastaların yakın takibi ve nefrotoksisiteye neden olabilecek diğer tedavilerinin kesilmesi veya doz ayarlanması kolistine bağlı gelişen akut böbrek yetmezliği riskini azaltabilir.

Çalışma Sakarya Üniversitesi Girişimsel Olmayan Klinik Araştırmalar Etik Kurulu 09.11.2020 tarihli 611 numaralı onayı ile Helsinki Deklerasyonuna uyularak yapılmıştır. 


\section{Kaynaklar}

1. Platt R, Goldman RA, Hopkıns C. Epidemiology of nosocomial infections. Infectious Diseases. In: Gorbach SL, Bartlett JG, Blacklow NR, eds. Philadelphia: WB Sounders Company; 1992. p. 96-106.

2. Larsen AR. Nosocomial infections. In: Hoeprich PD, Jordan MC, eds. Infectious Disease 4th. ed Phledelpiha: J.B.Lippincott Company, 35-40, 1989

3. Usluer G. 21.Yüzyllda hastane enfeksiyonlarl: neredeyiz? Türkiye Klinikleri Enfeksiyon Hastalıkları Özel Sayısı 2010;3(1):1-4.

4. Li J, Nation RL, Milne RW, Turnidge JD, Coulthard K. Evaluation of colistin as an agent against multi-resistant Gram-negative bacteria. Int J Antimicrob Agents. 2005 Jan;25(1):1125.

5. Falagas ME, Kasiakou SK. Colistin: The revival of polymyxins for the management of multidrug-resistant gram-negative bacterial infections. Clin Infect Dis 2005; 40:1333-41.

6. Akajagbor DS, Wilson SL, Shere-Wolfe KD, Dakum P, Charurat ME, Gilliam BL. Higher incidence of acute kidney injury with intravenous colistimethate sodium compared with polymyxin B in critically ill patients at a tertiary care medical center. Clin Infect Dis. 2013 Nov;57(9):1300-3.

7. Rigatto MH, Behle TF, Falci DR, et al. Risk factors for acute kidney injury (AKI) in patients treated with polymyxin B and influence of AKI on mortality: a multicentre prospective cohort study. The Journal of Antimicrobial Chemotherapy. 2015 May;70(5):1552-1557.

8. Pogue JM, Lee J, Marchaim D, Yee V, Zhao JJ, Chopra T, Lephart P, Kaye KS. Incidence of and risk factors for colistin-associated nephrotoxicity in a large academic health system. Clin Infect Dis. 2011 Nov;53(9):879-84.

9. Garonzik SM, Li J, Thamlikitkul V, Paterson DL, Shoham S, Jacob J, Silveira FP, Forrest A, Nation RL. Population pharmacokinetics of colistin methanesulfonate and formed colistin in critically ill patients from a multicenter study provide dosing suggestions for various categories of patients. Antimicrob Agents Chemother. 2011 Jul;55(7):3284-94.

10. Kubin CJ, Ellman TM, Phadke V, Haynes LJ, Calfee DP, Yin MT. Incidence and predictors of acute kidney injury associated with intravenous polymyxin B therapy. J Infect. 2012 Jul;65(1):80-7.

11. Kwon JA, Lee JE, Huh W, Peck KR, Kim YG, Kim DJ, Oh HY. Predictors of acute kidney injury associated with intravenous colistin treatment. Int J Antimicrob Agents. 2010 May;35(5):473-7.
12. Deryke CA, Crawford AJ, Uddin N, Wallace MR. Colistin dosing and nephrotoxicity in a large community teaching hospital. Antimicrob Agents Chemother. 2010 Oct;54(10):4503-5.

13. Giamarellou H. Multidrug-resistant Gram-negative bacteria: how to treat and for how long. Int J Antimicrob Agents. 2010 Dec;36 Suppl 2:S50-4.

14. Leite TT, Macedo E, Pereira SM, et al. Timing of renal replacement therapy initiation by AKIN classification system. Critical Care 2013; 17: R62.

15. Li J, Turnidge J, Milne R, Nation RL, Coulthard K. In vitro pharmacodynamic properties of colistin and colistin methanesulfonate against Pseudomonas aeruginosa isolates from patients with cystic fibrosis. Antimicrob Agents Chemother. 2001 Mar;45(3):781-5.

16. Vaara M. Polymyxins and their novel derivatives. Curr Opin Microbiol. 2010 Oct;13(5):57481.

17. Rocco M, Montini L, Alessandri E, Venditti M, Laderchi A, De Pascale G, RaponiG, Vitale $M$, Pietropaoli P, Antonelli $M$. Risk factors for acute kidney injury in critically ill patients receiving high intravenous doses of colistin methanesulfonate and/or other nephrotoxic antibiotics: a retrospective cohort study. Crit Care. 2013 Aug 14;17(4)

18. Inci A, Toker MK, Bicer IG, Derbent A, Salihoglu Z. Determination of colistin-related nephrotoxicity and risk factors in intensive care unit. North Clin Istanb. 2018 Apr 11;5(2):120124 .

19. Koksal I, Kaya S, Gencalioglu E, Yilmaz G. Evaluation of Risk Factors for Intravenous Colistin Use-related Nephrotoxicity. Oman Med J. 2016 Jul;31(4):318-21.

20. Aydoğan BB, Yildırım F, Zerman A, Gönderen K, Türkoğlu M, Aygencel G. Colistin nephrotoxicity in the ICU: Is it different in the geriatric patients? Aging Clin Exp Res. 2018 Jun;30(6):573-580.

21. Demirtürk N, Demir S, Așç Z, Doğan N. Evaluation of renal functions in patients treated with colistin. Nobel Med 2016; 12: 74-8

22. Kaya M, Tunçel YI, Kuru RN, Menteș S, Ünver S, Çeken S, et al. Retrospective Evaluation of Colistin Associated Nephrotoxicity at Oncology Hospital Intensive Care Unit. J Turk Soc Intens Care. 2014;12:51-6.

23. Inci A, Karabay A, Erus S, Demiraran Y. Nosocomial Infections and Associated Risk Factors in Geriatric Patients in the Intensive Care Unit. Eurasian J Emerg Med. 2016;15:177-80. 